\title{
Coexistence of Trunk or Lower Extremity Pain with Elbow and/or Shoulder Pain among Young Overhead Athletes: A Cross- Sectional Study
}

\author{
Takuya Sekiguchi, ${ }^{1}$ Yoshihiro Hagiwara, ${ }^{1,2}$ Haruki Momma, ${ }^{3}$ Masahiro Tsuchiya, ${ }^{4}$ \\ Kaoru Kuroki, ${ }^{2,5}$ Kenji Kanazawa, ${ }^{1}$ Yutaka Yabe, ${ }^{1}$ Shinichiro Yoshida, ${ }^{1}$ \\ Masashi Koide, ${ }^{1}$ Nobuyuki Itaya, ${ }^{1}$ Eiji Itoi ${ }^{1}$ and Ryoichi Nagatomi ${ }^{2,3}$ \\ ${ }^{1}$ Department of Orthopaedic Surgery, Tohoku University School of Medicine, Sendai, Miyagi, Japan \\ ${ }^{2}$ Department of Medicine and Science in Sports and Exercise, Tohoku University Graduate School of Medicine, \\ Sendai, Miyagi, Japan \\ ${ }^{3}$ Division of Biomedical Engineering for Health and Welfare, Tohoku University Graduate School of Biomedical \\ Engineering, Sendai, Miyagi, Japan \\ ${ }^{4}$ Department of Nursing, Faculty of Health Science, Tohoku Fukushi University, Sendai, Miyagi, Japan \\ ${ }^{5}$ Department of Rehabilitation, Tohoku Fukushi University, Sendai, Miyagi, Japan
}

\begin{abstract}
Elbow or shoulder injuries are common in overhead sports. Because energy derived from the lower extremity passes through the trunk to the upper extremity in overhead motion, a break in such a kinetic chain could lead to arm injuries. However, there is only limited information about the role of the trunk and lower extremity support in preventing elbow or shoulder injuries. This study aimed to explore the association of trunk and lower extremity pain with elbow/shoulder pain among young overhead athletes. We conducted a cross-sectional study using self-reported questionnaires mailed to young athletes belonging to the Miyagi Amateur Sports Association. The final study population comprised 2,215 young athletes playing baseball $(n=1,422)$, volleyball $(n=546)$, softball $(n=14)$, handball $(n=28)$, tennis $(n=$ $110)$, or badminton $(n=95)$. The median age of the participants was 11 years (range: 6 to 15 years). Multiple logistic regression analysis revealed the higher prevalence of elbow and/or shoulder pain in athletes with back pain $(\mathrm{OR}=5.52,95 \% \mathrm{Cl}=3.51-8.69)$, hip pain $(\mathrm{OR}=6.13,95 \% \mathrm{Cl}=3.35-11.22)$, knee pain $(\mathrm{OR}=2.28,95 \% \mathrm{Cl}=1.48-3.51)$, and foot pain $(\mathrm{OR}=3.03,95 \% \mathrm{Cl}=1.95-4.72)$, compared with those without pain. We propose that trunk or lower extremity pain is significantly associated with elbow or shoulder pain among young overhead athletes. Assessing for pain in trunk or lower extremity, as well as elbow and/or shoulder pain, may help prevent serious injuries in young overhead athletes.
\end{abstract}

Keywords: elbow and shoulder pain; lower extremity; overhead sports; trunk; young athletes Tohoku J. Exp. Med., 2017 November, 243 (3), 173-178. C 2017 Tohoku University Medical Press

\section{Introduction}

Elbow and/or shoulder injuries are common in overhead sports such as baseball, volleyball, handball, and tennis (Lyman et al. 2001, 2002; Connor et al. 2003; Andersson et al. 2017). Continuing to play overhead sports with symptoms in the arm has previously been linked to serious arm injuries (e.g., medial collateral ligament injuries (Chen et al. 2001), osteochondritis dissecans in the elbow (Koh and Dietz 2005; Furushima et al. 2015), rotator cuff tears (Braun et al. 2009), and superior labrum anteriorposterior lesions in the shoulder (Han et al. 2009), and elbow and shoulder surgeries among young players has increased annually (Fleisig et al. 2011)). The elbow and shoulder are subjected to considerable forces, acceleration, and repetitive stress (Kibler 1993; Limpisvasti et al. 2007), which are assumed to induce their injuries. Numerous intrinsic and extrinsic factors including age (Lyman et al. 2001), muscle weakness around the shoulder (Trakis et al. 2008; Edouard et al. 2013), level of competition (Pluim et al. 2006), and frequency and volume of play (Pluim et al. 2006) have been reported as risk factors for elbow and shoulder injuries in overhead athletes. Due to the potential risk for elbow and shoulder injuries, some authors have suggested that young athletes should be limited in their participation of sports (Lyman et al. 2002; Petty et al. 2004).

During the overhead motion of baseball throwing, volley ball spiking, and tennis serving, the elbow and shoulder

\footnotetext{
Received September 20, 2017; revised and accepted November 7, 2017. Published online November 21, 2017; doi: 10.1620/tjem.243.173. Correspondence: Yoshihiro Hagiwara, Tohoku University School of Medicine, 2-1 Seiryo-machi, Aoba-ku, Sendai, Miyagi 980-8574,

e-mail: hagi@med.tohoku.ac.jp
} Japan. 
form part of the kinetic energy chain (Kibler 1995; MacWilliams et al. 1998; Burkhart et al. 2003; Forthomme et al. 2005). The concept of the kinetic chain is that coordinated motion derives energy from the lower extremity through the trunk up to the upper extremity (Burkhart et al. 2003). Imbalance at any point of the kinetic chain could affect elbow and shoulder injuries (Reinold et al. 2010). Several studies have reported that biomechanical dysfunction of the trunk or lower extremities, involving core stability, hip range of motion, and foot posture, are related to elbow and shoulder injuries among various high-level adult athletes (Scher et al. 2010; Feigenbaum et al. 2013; Chaudhari et al. 2014; Pontillo et al. 2014). However, there is little evidence focusing on the association between lack of sufficient support in the trunk or lower extremities and injuries to the elbow and shoulder among young athletes. One study reported no association of core muscle endurance with elbow and shoulder injuries in junior high school baseball players (Endo and Sakamoto 2014). Although low back pain and knee pain were significantly associated with elbow and shoulder pain among young baseball players, data regarding hand dominance and other pain locations were not included (Sekiguchi et al. 2016). Considering the kinetic chain, it is important to investigate the association of symptoms in the trunk (including the back and the hip) and lower extremities (including the knee and the foot) with pain in the elbow and shoulder among other overhead athletes, as well as among baseball players. The purpose of this study was to investigate the association of trunk or lower extremity pain with pain in the elbow and/or shoulder among young overhead athletes.

\section{Methods}

\section{Participants}

The study protocol was reviewed and approved by the Ethics Committee on Research of Human Subjects at the Tohoku University Graduate School of Medicine (approval number: 2013-1-564). School-aged athletes belonging to the Miyagi Amateur Sports Association, established with the aim of promoting youth health through various sports, participated in the study (Sekiguchi et al. 2016). This organization held contact information for 25,469 registered athletes and their parents. Self-reported questionnaires and informed consent documents were mailed to all registered athletes in October, 2014. In December, 2014, a total of 7,333 athletes had replied with both written informed consent and a completed questionnaire (response rate: $28.8 \%$ ). Respondents who did not play overhead sports, which include baseball, softball, handball, tennis, badminton, or volleyball $(n=4,548)$ or who played both these sports and other sports $(n=34)$ were excluded from this study. Furthermore, participants with missing data were excluded $(\mathrm{n}=536)$. The final study population comprised 2,215 young athletes (Fig. 1). In this study, we included the same baseball players as in a previous study (Sekiguchi et al. 2016).

\section{Pain information}

Musculoskeletal pain was assessed using the self-reported questionnaire. The question regarding the presence of pain was as follows: "Do you have pain in any part of your body now? If yes, please identify the location of the pain (multiple choices are permitted)." The anatomical areas and names were illustrated using a drawing. Participants who identified the dominant side of the shoulder and elbow were regarded as having elbow and/or shoulder pain present; whereas participants who identified pain in the back/low back, hip, knee, and ankle-foot regions were regarded as having pain present in the back, hip, knee, and foot, respectively.

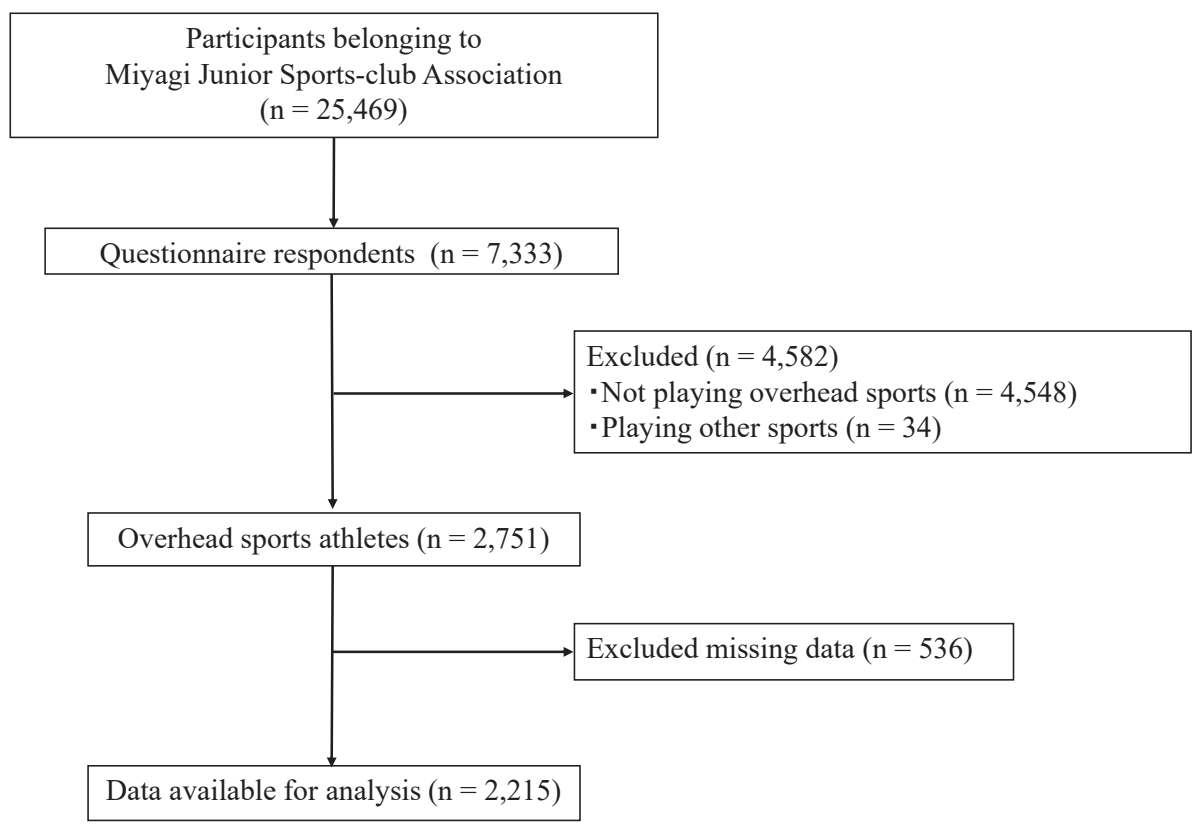

Fig. 1. Flowchart of this study. 


\section{Covariates}

Sex, age, body mass index (BMI), years of athletic experience, competitive level, the type of sport, the number of hours spent training per day on weekdays and weekends, the number of days spent participating in sports activities per week, practice intensity, and sleep duration were evaluated using the self-reported questionnaire. The following continuous variables were divided into categories, according to distribution and clinical significance, as follows: age was categorized into three groups ( 6 to 9 years, 10 and 11 years, and 12 to 15 years); number of years of experience playing the sports into three groups ( $<1,1$ to Pain $<3$, and $\geq 3$ years); number of hours in practice per day on weekdays and weekends into two groups (on weekdays: $\leq 2$ and $>2$ hours, on weekends: $\leq 4$ and $>4$ hours); number of days participating in team practice and game(s) per week into three groups ( $\leq 2,3$ to 4 , and 5 to 7 days); and sleeping duration into three groups ( $\leq 8,>8$ to 9 , and $>9$ hours).

Pre-coded questions including competitive levels (national competition, Tohoku distinct competition, prefectural competition, local competition, and recreation only), type of sport (baseball, softball, handball, tennis, badminton, and volleyball), and the practice intensity (hard and not hard) were also evaluated. The competitive level was categorized into two groups according to the following distribution: high level; "prefectural competition or higher" and low; "local competition or recreation level only."

\section{Statistical analysis}

Continuous variables were presented as medians with an inter- quartile range (IQR), and categorical variables were presented as a percentage (\%). First, multiple logistic regression analysis was conducted to examine the association between pain in the trunk and lower extremities (back, hip, knee, and foot) and elbow and/or shoulder pain. The odds ratio (OR) and $95 \%$ confidential intervals $(95 \%$ CI) for the presence of elbow and/or shoulder pain were calculated after simultaneous adjustment for potential covariates.

Variables considered in the models were sex (male or female), age (6 to 9,10 and 11 , or 12 to 15 years), BMI (continuous variable), years of athletic experience $(<1,1$ to $<3$, or $\geq 3$ years), the participant's sport (baseball, softball, handball, tennis, badminton, or volleyball), competitive level (low or high), amount of practice per day on weekdays ( $\leq 2$ or $>2$ hours) and weekends ( $\leq 4$ or $>4$ hours), number of days participating in team practices and number of games per week ( $\leq 2,3$ and 4 , or $\geq 5$ days), practice intensity (hard or not hard), sleeping duration ( $\leq 8,>8$ to 9 , or $>9$ hours), and the presence of back, hip, knee, and foot pain, respectively. To check for potential collinearity between exposures and covariates, we calculated the variance inflation factors (VIFs).

All statistical analyses were performed with SPSS version 24.0 (SPSS Japan Inc., Tokyo, Japan). All tests were 2-tailed, and $\mathrm{P}<0.05$ was considered statistically significant.

\section{Results}

Basic characteristics of the participants are shown in Table 1. The median age of the participants was 11 (IQR,

Table 1. Basic characteristics of young overhead athletes $(n=2,215)$.

\begin{tabular}{|c|c|c|c|}
\hline Variables & Categories & Median (IQR) & Number (Percentage) \\
\hline \multirow[t]{2}{*}{$\overline{\operatorname{Sex}}$} & Male & & $1,583(71.5)$ \\
\hline & Female & & $632(28.5)$ \\
\hline \multirow[t]{4}{*}{ Age (years) } & & $11.0(10.0-12.0)$ & \\
\hline & 6 to 9 & & $453(20.5)$ \\
\hline & 10 and 11 & & $915(41.3)$ \\
\hline & 12 to 15 & & $847(38.2)$ \\
\hline BMI & & $17.7(16.1-19.5)$ & \\
\hline \multirow[t]{3}{*}{ Experience (years) } & $<1$ & & $340(15.3)$ \\
\hline & 1 to $<3$ & & $1,164(52.6)$ \\
\hline & $\geq 3$ & & $711(32.1)$ \\
\hline \multirow[t]{6}{*}{ Types of sports } & Baseball & & $1,422(64.2)$ \\
\hline & Softball & & $14(0.6)$ \\
\hline & Handball & & $28(1.3)$ \\
\hline & Tennis & & $110(5.0)$ \\
\hline & Badminton & & $95(4.3)$ \\
\hline & Volleyball & & $546(24.7)$ \\
\hline \multirow[t]{2}{*}{ Competitive level } & Low & & $1,351(61.0)$ \\
\hline & High & & $864(39.0)$ \\
\hline \multirow[t]{3}{*}{ Practice per day weekdays (hrs) } & & $2.0(1.0-2.3)$ & \\
\hline & $\leq 2$ & & $1,656(74.8)$ \\
\hline & $>2$ & & $559(25.2)$ \\
\hline \multirow[t]{3}{*}{ Practice per day weekends (hrs) } & & $4.0(3.0,6.0)$ & \\
\hline & $\leq 4$ & & $1,185(53.5)$ \\
\hline & $>4$ & & $1,030(46.5)$ \\
\hline \multirow[t]{4}{*}{ Training per week (days) } & & $3.0(2.0-4.0)$ & \\
\hline & $\leq 2$ & & $726(32.8)$ \\
\hline & 3 to 4 & & $1,030(46.5)$ \\
\hline & 5 to 7 & & $459(20.7)$ \\
\hline \multirow[t]{2}{*}{ Practice intensity } & Not hard & & $1,401(63.3)$ \\
\hline & Hard & & $814(36.7)$ \\
\hline \multirow[t]{4}{*}{ Sleep duration (hrs) } & & $8.9(8.3-9.3)$ & \\
\hline & $\leq 8$ & & $391(17.7)$ \\
\hline & $>\overline{8}$ to 9 & & $1,036(46.8)$ \\
\hline & $>9$ & & $788(35.6)$ \\
\hline
\end{tabular}


10-12) years. The median height and weight were 145.0 (IQR, 137.0-154.0) $\mathrm{cm}$ and 38.0 (IQR, 31.0-45.0) kg, respectively.

The prevalence of pain in the elbow and/or shoulder comprised $10.2 \%(n=225)$, in the elbow $5.3 \%(n=119)$, in the shoulder $6.5 \%(\mathrm{n}=143)$, and in both the elbow and shoulder $1.7 \%(\mathrm{n}=37)$, respectively. The prevalence of pain in the non-dominant elbow and shoulder was $0.8 \%$ (n $=17)$ and $0.3 \%(\mathrm{n}=7)$, respectively. The prevalence of pain according to the type of sports is shown in Table 2 . The prevalence of elbow and/or shoulder pain did not indicate a statistically significant difference among the types of sport.

Table 3 shows the association of pain in the trunk and lower extremities with that in the elbow and/or shoulder as assessed using logistic regression analyses. Among the athletes, those who had pain in the back, hip, knee, and foot comprised $44.7 \%(n=63), 55.4 \%(n=36), 30.4 \%(n=58)$, and $31.3 \%(\mathrm{n}=51)$, respectively. Adjusted ORs $(95 \% \mathrm{CI})$ for pain in the elbow/shoulder with that in the back were 5.52 (3.51-8.69), in the hip 6.13 (3.35-11.22), in the knee $2.28(1.48-3.51)$, and in the foot 3.03 (1.95-4.72), respectively. VIFs were low, ranging from 1.02 to 1.47 , suggesting that collinearity among the adjusted variables was not a significant problem.

\section{Discussion}

The most important finding of this study was that the prevalence of low back, hip, knee, or foot pain was significantly higher among young overhead athletes with elbow and/or shoulder pain. Furthermore, the pain in the elbow and/or shoulder more frequently coexisted with the pain in the back and hip, compared with the knee and foot.

Several studies have reported that dysfunction in the trunk or lower extremities has a significant association with elbow and shoulder injuries in adult overhead athletes (Scher et al. 2010; Feigenbaum et al. 2013; Garrison et al. 2013; Chaudhari et al. 2014; Pontillo et al. 2014; Radwan et al. 2014). Some studies have demonstrated that poor core stability should be considered as a potential risk factor for elbow and shoulder injuries (Garrison et al. 2013; Chaudhari et al. 2014; Pontillo et al. 2014; Radwan et al. 2014). Other studies have shown an association between hip range of motion, as well as foot posture, with elbow and shoulder injuries. Scher et al. (2010) reported that dominant hip extension and shoulder external rotation were independently correlated with shoulder injuries in professional baseball players. Further, Feigenbaum et al. (2013) reported the association of an abnormal foot arch posture with a history of elbow and shoulder surgeries in collegiate and professional baseball pitchers. Among young athletes, there is little evidence evaluating the association between dysfunction of the trunk or lower extremities and elbow and shoulder injuries. Although Endo and Sakamoto (2014) reported no association of core muscle endurance with elbow or shoulder injuries, the present study revealed sig-

Table 2. The prevalence of pain according to sport type $(n=2,215)$.

\begin{tabular}{lccccccc}
\hline & & \multicolumn{6}{c}{ Type of sport } \\
\cline { 2 - 8 } & & Baseball & Softball & Handball & Tennis & Badminton Volleyball \\
& & 1,422 & 14 & 28 & 110 & 95 & 546 \\
Pain location & presence, $\mathrm{n}$ & $\mathrm{n}(\%)$ & $\mathrm{n}(\%)$ & $\mathrm{n}(\%)$ & $\mathrm{n}(\%)$ & $\mathrm{n}(\%)$ & $\mathrm{n}(\%)$ \\
\hline Elbow/shoulder & 225 & $152(10.7)$ & $1(7.1)$ & $2(7.1)$ & $12(10.9)$ & $9(9.5)$ & $49(9.0)$ \\
Back & 141 & $61(4.3)$ & $1(7.1)$ & $5(17.9)$ & $13(11.8)$ & $6(6.3)$ & $55(10.1)$ \\
Hip & 65 & $37(2.6)$ & 0 & $4(14.3)$ & $3(2.7)$ & $4(4.2)$ & $17(3.1)$ \\
Knee & 191 & $89(6.3)$ & $2(14.3)$ & $8(28.6)$ & $12(10.9)$ & $14(14.7)$ & $66(12.1)$ \\
Foot & 163 & $79(5.6)$ & 0 & $5(17.9)$ & $10(9.1)$ & $17(17.9)$ & $52(9.5)$ \\
\hline
\end{tabular}

Table 3. Association of pain in the trunk and lower extremities with that in the elbow and/or shoulder among young overhead athletes $(n=2,215)$.

\begin{tabular}{|c|c|c|c|c|c|c|}
\hline \multirow[b]{2}{*}{ Pain location } & & \multirow[b]{2}{*}{$\mathrm{n}$} & \multicolumn{3}{|c|}{ Elbow and/or shoulder pain } & \multirow[b]{2}{*}{$\mathrm{P}$ value } \\
\hline & & & presence, $\mathrm{n}(\%)$ & OR $(95 \% \mathrm{CI})^{*}$ & Adjusted OR $(95 \% \mathrm{CI})^{* *}$ & \\
\hline \multirow[t]{2}{*}{ Back } & - & 2074 & $162(7.8)$ & 1 & 1 & \\
\hline & + & 141 & $63(44.7)$ & $9.53(6.59-13.78)$ & $5.52(3.51-8.69)$ & $<0.001$ \\
\hline \multirow[t]{2}{*}{ Hip } & - & 2150 & $189(8.8)$ & 1 & 1 & \\
\hline & + & 65 & $36(55.4)$ & $12.88(7.72-21.48)$ & $6.13(3.35-11.22)$ & $<0.001$ \\
\hline \multirow[t]{2}{*}{ Knee } & - & 2024 & $167(8.3)$ & 1 & 1 & \\
\hline & + & 191 & $58(30.4)$ & $4.85(3.43-6.86)$ & $2.28(1.48-3.51)$ & $<0.001$ \\
\hline \multirow[t]{2}{*}{ Foot } & - & 2052 & $174(8.5)$ & 1 & 1 & \\
\hline & + & 163 & $51(31.3)$ & $4.92(3.41-7.09)$ & $3.03(1.95-4.72)$ & $<0.001$ \\
\hline
\end{tabular}

*Crude model.

**Adjusted for sex (male or female), age (6 to 9,10 and 11, or 12 to $15 \mathrm{y}$ ), BMI (continuous variable), years of athletic experience $(<1,1$ to $<3$, or $\geq 3$ y), types of sports (baseball, softball, handball, tennis, badminton, or volleyball), competitivelevel (high or low), amount of practice per day weekdays $(\leq 2$, or $>2 \mathrm{hrs})$ and weekends $(\leq 4$, or $>4 \mathrm{hrs})$, training per week $(\leq 3,4$ and 5 , or 6 and 7 days), practice intensity (hard, or not hard), sleep dutation $(\leq 8,>8$ to 9 , or $>9$ hrs), and the presence of back, hip, knee, and foot pain. 
nificant relationships between pain in the trunk or lower extremities and pain in the elbow and/or shoulder among young overhead athletes. This result is consistent with a previous study that showed significant associations of pain in the low back or knee with elbow and shoulder pain in young baseball players (Sekiguchi et al. 2016). Possible explanations for these associations are as follows. First, repetitive overhead motion could affect all body parts not only in the upper extremities but also in the trunk and lower extremities. Overhead motion is a part of the kinetic chain that produces energy from the lower extremity, through the trunk, and subsequently releases it through the upper extremities (MacWilliams et al. 1998; Burkhart et al. 2003; Limpisvasti et al. 2007). Furthermore, the trunk and lower extremities decelerate at the end of the motion (Matsuoka et al. 1994), which can be assumed to induce more stress and pain in the elbow and shoulder. Second, the disturbance of the kinetic chain due to pain in the trunk or lower extremities could affect elbow and shoulder pain. Although a causal relationship between pain in the trunk and lower extremity and pain in the elbow and shoulder could not be assessed in this study, it is well known that imbalance at any point of the kinetic chain can influence elbow and shoulder injuries (Burkhart et al. 2003; Reinold et al. 2010). Pain in the trunk or lower extremities could be a possible sign of disturbance in the kinetic chain; therefore, it is important to pay attention to pain there, together with elbow and shoulder pain.

Our study showed that the associations between pain in the trunk (including back and hip) and that in the elbow and shoulder have a much stronger connection than that in the lower extremities (including the knee and foot). The trunk are assumed to have important roles in generating power during overhead motion (e.g., throwing a ball, serving a ball with and without racket, and spiking), with rotation of the trunk, and tilting the spine regardless of ground contact (Young et al. 1998; Elliott 2006; Fortenbaugh et al. 2009; Wagner et al. 2014). Some biomechanical studies have demonstrated that the physical load on the trunk is higher than that on other body parts (Happee and Van der Helm 1995; Kibler 1995). The larger core muscles in the body can generate greater force during the overhead motion in serving in tennis (Kibler 1995). Kibler (1995) described how the trunk generated $51 \%$ of the energy used during tennis motions whereas the shoulder did $13 \%$ of the work. In throwing motions, the periscapular and trunk muscles have responsibility for approximately $85 \%$ of the muscle activation (Happee and Van der Helm 1995). These findings are consistent with our results, and further research is needed to evaluate the association of dysfunction in the trunk or lower extremities with elbow and shoulder injuries in young overhead athletes.

Our study has several implications. First, it was large enough to evaluate the association of pain in the trunk or lower extremities with that in the elbow and/or shoulder among young overhead athletes. Second, our results showed a strong association of the trunk or lower extremities with the upper extremities in young overhead athletes. The disturbance of the kinetic chain might result in elbow/ shoulder pain even though there was not a cause and effect relationship. It seems important therefore to check for pain in the trunk or lower extremities to help prevent serious injuries in young overhead athletes as well as in adult athletes. In addition, the trunk may play an important role among young overhead athletes. These results suggest that further research on young athletes should take into consideration the entire body and not just obviously injured areas. There are several limitations to this study. First, because this study design was cross-sectional, the effect of causal relationships could not be assessed (e.g., trunk or lower extremity pain resulting in elbow/shoulder pain). Second, we assessed pain information using a self-reported questionnaire, and therefore the underlying pathology of pain and pain-related disabilities was not evaluated. Third, there was weakness in the reliability of the measured instrument due to a lack of a test-retest. Finally, the response rate was low $(28.8 \%)$ and the present study may have been biased. Future studies should improve the participant recruitment process to increase generalizability and a prospective study should be conducted to clarify previously identified issues.

In conclusion, the prevalence of pain in the trunk or lower extremities was significantly higher among young overhead athletes with pain in the elbow and/or shoulder. The present study indicates that the pain in the trunk or lower extremities is associated with the pain in the elbow and/or shoulder among young overhead athletes.

\section{Acknowledgments}

This study was performed as part of the Miyagi Sports Medical Projects and supported by Asahi Breweries. The authors would like to thank the young athletes and staff belonging to the Miyagi Amateur Sports Association.

\section{Conflict of Interest}

The authors declare no conflict of interest.

\section{References}

Andersson, S.H., Bahr, R., Clarsen, B. \& Myklebust, G. (2017) Preventing overuse shoulder injuries among throwing athletes: a cluster-randomised controlled trial in 660 elite handball players. Br. J. Sports Med., 51, 1073-1080.

Braun, S., Kokmeyer, D. \& Millett, P.J. (2009) Shoulder injuries in the throwing athlete. J. Bone Joint Surg. Am., 91, 966-978.

Burkhart, S.S., Morgan, C.D. \& Kibler, W.B. (2003) The disabled throwing shoulder: spectrum of pathology Part III: the SICK scapula, scapular dyskinesis, the kinetic chain, and rehabilitation. Arthroscopy, 19, 641-661.

Chaudhari, A.M.W., McKenzie, C.S., Pan, X.L. \& Onate, J.A. (2014) Lumbopelvic control and days missed because of injury in professional baseball pitchers. Am. J. Sports Med., 42, 2734-2740.

Chen, F.S., Rokito, A.S. \& Jobe, F.W. (2001) Medial elbow problems in the overhead-throwing athlete. J. Am. Acad. Orthop. Surg., 9, 99-113.

Connor, P.M., Banks, D.M., Tyson, A.B., Coumas, J.S. \& D’Alessandro, D.F. (2003) Magnetic resonance imaging of 
the asymptomatic shoulder of overhead athletes: a 5-year follow-up study. Am. J. Sports Med., 31, 724-727.

Edouard, P., Degache, F., Oullion, R., Plessis, J.Y., GleizesCervera, S. \& Calmels, P. (2013) Shoulder strength imbalances as injury risk in handball. Int. J. Sports Med., 34, 654-660.

Elliott, B. (2006) Biomechanics and tennis. Br. J. Sports Med., 40, 392-396.

Endo, Y. \& Sakamoto, M. (2014) Correlation of shoulder and elbow injuries with muscle tightness, core stability, and balance by longitudinal measurements in junior high school baseball players. J. Phys. Ther. Sci., 26, 689-693.

Feigenbaum, L.A., Roach, K.E., Kaplan, L.D., Lesniak, B. \& Cunningham, S. (2013) The association of foot arch posture and prior history of shoulder or elbow surgery in elite-level baseball pitchers. J. Orthop. Sports Phys. Ther., 43, 814-820.

Fleisig, G.S., Andrews, J.R., Cutter, G.R., Weber, A., Loftice, J., McMichael, C., Hassell, N. \& Lyman, S. (2011) Risk of serious injury for young baseball pitchers: a 10-year prospective study. Am. J. Sports Med., 39, 253-257.

Fortenbaugh, D., Fleisig, G.S. \& Andrews, J.R. (2009) Baseball pitching biomechanics in relation to injury risk and performance. Sports health, 1, 314-320.

Forthomme, B., Croisier, J.L., Ciccarone, G., Crielaard, J.M. \& Cloes, M. (2005) Factors correlated with volleyball spike velocity. Am. J. Sports Med., 33, 1513-1519.

Furushima, K., Iwabu, S. \& Itoh, Y. (2015) Osteochondritis Dissecans of the Throwing Elbow. In Sports Injuries to the Shoulder and Elbow, edited by Park, J.Y., Springer, Berlin, Heidelberg, pp. 313-348.

Garrison, J.C., Arnold, A., Macko, M.J. \& Conway, J.E. (2013) Baseball players diagnosed with ulnar collateral ligament tears demonstrate decreased balance compared to healthy controls. J. Orthop. Sports Phys. Ther., 43, 752-758.

Han, K.J., Kim, Y.K., Lim, S.K., Park, J.Y. \& Oh, K.S. (2009) The effect of physical characteristics and field position on the shoulder and elbow injuries of 490 baseball players: confirmation of diagnosis by magnetic resonance imaging. Clin. J. Sport Med., 19, 271-276.

Happee, R. \& Van der Helm, F.C.T. (1995) The control of shoulder muscles during goal directed movements, an inverse dynamic analysis. J. Biomech., 28, 1179-1191.

Kibler, W. (1993) Evaluation of sports demands as a diagnostic tool in shoulder disorders. In The Shoulder: A Balance of Mobility and Stability, Rosemont, IL, edited by F. Matsen, F.,Fu, F., \& Hawkins, R.J., Amer Academy of Orthopaedic, Rosemont, IL, pp. 379-395.

Kibler, W. (1995) Biomechanical analysis of the shoulder during tennis activities. Clin. Sports Med., 14, 79-85.

Koh, J. \& Dietz, J. (2005) Osteoarthritis in other joints (hip, elbow, foot, ankle, toes, wrist) after sports injuries. Clin. Sports Med., 24, 57-70.

Limpisvasti, O., ElAttrache, N.S. \& Jobe, F.W. (2007) Understanding shoulder and elbow injuries in baseball. J. Am. Acad. Orthop. Surg., 15, 139-147.

Lyman, S., Fleisig, G.S., Andrews, J.R. \& Osinski, E.D. (2002)
Effect of pitch type, pitch count, and pitching mechanics on risk of elbow and shoulder pain in youth baseball pitchers. Am. J. Sports Med., 30, 463-468.

Lyman, S., Fleisig, G.S., Waterbor, J.W., Funkhouser, E.M., Pulley, L., Andrews, J.R., Osinski, E.D. \& Roseman, J.M. (2001) Longitudinal study of elbow and shoulder pain in youth baseball pitchers. Med. Sci. Sports Exer., 33, 1803-1810.

MacWilliams, B.A., Choi, T., Perezous, M.K., Chao, E.Y.S. \& McFarland, E.G. (1998) Characteristic ground-reaction forces in baseball pitching. Am. J. Sports Med., 26, 66-71.

Matsuoka, T., Tachibana, T., Nishikawa, H., Nojima, A., Hisamune, J., Nishihara, K., Masuda, K. \& Nobuhara, K. (1994) Analysis of cocking to acceleration phase during pitching. Jpn. J. Clin. Sport Med., 11, 601-606 (in Japanese).

Petty, D.H., Andrews, J.R., Fleisig, G.S. \& Cain, E.L. (2004) Ulnar collateral ligament reconstruction in high school baseball players: clinical results and injury risk factors. Am. J. Sports Med., 32, 1158-1164.

Pluim, B.M., Staal, J.B., Windler, G.E. \& Jayanthi, N. (2006) Tennis injuries: occurrence, aetiology, and prevention. Br. J. Sports Med., 40, 415-423.

Pontillo, M., Spinelli, B.A. \& Sennett, B.J. (2014) Prediction of in-season shoulder injury from preseason testing in division I collegiate football players. Sports Health, 6, 497-503.

Radwan, A., Francis, J., Green, A., Kahl, E., Maciurzynski, D., Quartulli, A., Schultheiss, J., Strang, R. \& Weiss, B. (2014) Is there a relation between shoulder dysfunction and core instability? Int. J. Sports Phys. Ther., 9, 8-13.

Reinold, M.M., Gill, T.J., Wilk, K.E. \& Andrews, J.R. (2010) Current concepts in the evaluation and treatment of the shoulder in overhead throwing athletes, part 2: injury prevention and treatment. Sports Health, 2, 101-115.

Scher, S., Anderson, K., Weber, N., Bajorek, J., Rand, K. \& Bey, M.J. (2010) Associations among hip and shoulder range of motion and shoulder injury in professional baseball players. $J$. Ath. Train., 45, 191-197.

Sekiguchi, T., Hagiwara, Y., Momma, H., Tsuchiya, M., Kuroki, K., Kanazawa, K., Yabe, Y., Koide, M., Itaya, N., Itoi, E. \& Nagatomi, R. (2016) Youth baseball players with elbow and shoulder pain have both low back and knee pain: a crosssectional study. Knee Surg. Sports Traumatol. Arthrosc, doi: 10.1007/s00167-016-4364-y [Epub ahead of print].

Trakis, J.E., McHugh, M.P., Caracciolo, P.A., Busciacco, L., Mullaney, M. \& Nicholas, S.J. (2008) Muscle strength and range of motion in adolescent pitchers with throwing-related pain: implications for injury prevention. Am. J. Sports Med., 36, 2173-2178.

Wagner, H., Pfusterschmied, J., Tilp, M., Landlinger, J., von Duvillard, S.P. \& Muller, E. (2014) Upper-body kinematics in team-handball throw, tennis serve, and volleyball spike. Scand. J. Med. Sci. Sports, 24, 345-354.

Young, J., Casazza, B. \& Press, J. (1998) Biomechanical aspects of the spine in pitching. In Injuries in baseball, edited by Andrews, J., Zarins, B. \& Wikl, K., Lippincott-Raven, Philadelphia, pp. 30-43. 